This item was submitted to Loughborough's Research Repository by the author.

Items in Figshare are protected by copyright, with all rights reserved, unless otherwise indicated.

\title{
Hot water immersion induces an acute cytokine response in cervical spinal cord injury
}

PLEASE CITE THE PUBLISHED VERSION

http://dx.doi.org/10.1007/s00421-015-3206-9

\section{PUBLISHER}

(C) Springer Verlag

\section{VERSION}

AM (Accepted Manuscript)

\section{PUBLISHER STATEMENT}

This work is made available according to the conditions of the Creative Commons Attribution-NonCommercialNoDerivatives 4.0 International (CC BY-NC-ND 4.0) licence. Full details of this licence are available at: https://creativecommons.org/licenses/by-nc-nd/4.0/

\section{LICENCE}

CC BY-NC-ND 4.0

\section{REPOSITORY RECORD}

Leicht, Christof A., Ken Kouda, Yasunori Umemoto, M. Banno, Tokio Kinoshita, T. Moriki, T. Nakamura, Nicholas C. Bishop, Victoria L. Goosey-Tolfrey, and Fumihiro Tajima. 2019. "Hot Water Immersion Induces an Acute Cytokine Response in Cervical Spinal Cord Injury". figshare. https://hdl.handle.net/2134/18706. 
Hot water immersion induces an acute cytokine response in cervical spinal cord injury

Leicht C.A. ${ }^{2}$, Kouda K. ${ }^{1}$, Umemoto Y. ${ }^{1}$, Banno M. ${ }^{1}$, Kinoshita T. ${ }^{1}$, Moriki T. ${ }^{1}$, Nakamura T. ${ }^{1}$, Bishop N.C. $^{2}$, Goosey-Tolfrey V.L. ${ }^{2}$, Tajima F. ${ }^{1}$

${ }^{1}$ Department of Rehabilitation Medicine, Wakayama Medical University, Wakayama, Japan

${ }^{2}$ The Peter Harrison Centre for Disability Sport; School of Sport, Exercise, and Health Sciences;

Loughborough University; Loughborough; UK

Running head: Core temperature and the cytokine response in tetraplegia

\section{Corresponding author}

Dr Christof Leicht; The Peter Harrison Centre for Disability Sport; School of Sport, Exercise, and Health Sciences; Loughborough University; Loughborough; UK

E-mail: c.a.leicht@lboro.ac.uk

Tel: +44 1509226306

Fax: +44 1509226301 


\begin{abstract}
Purpose: The dysfunctional sympathetic nervous system in individuals with cervical spinal cord injury (CSCI) impairs adrenergic responses and may therefore contribute to the blunted postexercise cytokine response. The purpose of this study was to investigate an alternative way to exercise to induce an acute cytokine response by passive core temperature elevation in CSCI. Methods: Seven male participants with a motor complete CSCI and 8 male able-bodied controls were immersed for $60 \mathrm{~min}$ in water set at a temperature $2{ }^{\circ} \mathrm{C}$ above the individuals' resting oesophageal temperature. Blood was collected pre, post, and every hour up to $4 \mathrm{~h}$ post immersion. Results: Hot water immersion resulted in an IL-6 plasma concentration mean increase of $133 \pm 144 \%$ in both groups $(\mathrm{P}=0.001)$. On a group level, IL-6 plasma concentrations were $68 \pm 38 \%$ higher in CSCI $(\mathrm{P}=0.06)$. Hot water immersion increased interleukin-6 (IL-6) by $133 \pm 144 \%$ in both groups $(P=0.001)$, with a $68 \pm 38 \%$ higher average $\mathrm{IL} 6$ concentration in $\operatorname{ESCI}(\mathrm{P}=0.06)$. In both groups, IL-8 increased by $14 \pm 11 \%(\mathrm{P}=0.02)$ and IL-1ra by $18 \pm 17 \%$ $(\mathrm{P}=0.05)$. Catecholamine plasma concentrations were significantly reduced in CSCI $(\mathrm{P}<0.05)$ and did not increase following immersion. Conclusions: Passive elevation of core temperature acutely elevates IL-6, IL-8 and IL-1ra in CSCI despite a blunted adrenergic response, which is in contrast to earlier exercise interventions in CSCI. The present study lays the foundation for future studies to explore water immersion as an alternative to exercise to induce an acute cytokine response in CSCI.
\end{abstract}

Key words: cytokines; immune function; tetraplegia; non-exercise intervention 


\section{Abbreviations}

AB able-bodied

ASIA American spinal injury association impairment scale

C cervical

CD cluster of differentiation

CSCI cervical spinal cord injury

$\mathrm{CV} \quad$ coefficient of variation

IL interleukin

IL-1ra interleukin-1 receptor antagonist

mRNA messenger ribonucleic acid

sICAM soluble intercellular adhesion molecule

TNF tumor necrosis factor 


\section{Introduction}

Core temperature rises when performing exercise exceeding a minimal duration and intensity, and a number of immune parameters increase following exercise. These include leukocyte and lymphocyte subset numbers, in addition to cytokine secretion (Walsh and Whitham 2006). Elevated core temperature is only one aspect contributing to exercise-related alterations in immune parameters; for example, adrenergic factors have also been shown to be independent influencers (Nagao et al. 2000; Starkie et al. 2001). When artificially raising body temperature via heat exposure or hot water immersion, temperature effects can be investigated in isolation, independently of muscle contraction. Such interventions also impact on immunity and increase immune cell counts and cytokine secretion (Laing et al. 2008). This has been attributed to heat shock factors (Welc and Clanton 2013) and the core-temperature related increases of stress hormones acting on adrenergic receptors on immune cells (Kappel et al. 1991), even though these increases are more modest when at rest than during exercise.

A spinal cord injury increases the risk of infection; therefore, infections pose a common problem in this population (Cardenas et al. 2004). The dysfunctional sympathetic nervous system in cervical spinal cord injury $(\mathrm{CSCI})$ reduces adrenergic responses and may therefore contribute to depressed immunity (Yamanaka et al. 2010). Furthermore, the loss of muscle function following spinal cord injury may reduce the ability to perform sufficient amounts of exercise to induce significant-positive changes in immune parameters and reduce the ability to cough, increasing the risk for infection. This is particularly relevant for those with a cervical spinal cord injury (CSCI) who experience more severe impairments and higher mortality rates (DeVivo et al. 1999). 
Individuals with a CSCI are also more likely to be in a state of chronic low grade inflammation.

This conditionChronic low grade inflammation, as evidenced by elevated circulating levels of pro-inflammatory markers at rest, has been linked to elevated risk of several chronic diseases, such as cardiovascular disease, some cancer types, and Type 2 Diabetes (Gleeson et al. 2011). In able bodied populations, exercise acutely elevates pro-inflammatory cytokines, but this is rapidly followed by an increase in circulating concentrations of anti-inflammatory cytokines. It has been suggested that with repeated moderate-vigorous exercise, the recurrent and longer lasting antiinflammatory response reduces levels of pro-inflammatory cytokines, such as interleukin-6 (IL6), at rest (Gleeson et al. 2011). The cytokine response - in the specific case of IL-6 - is governed by muscle-contraction dependent and sympathetic nervous system mediated signalling pathways (Welc and Clanton 2013). This may explain the blunted cytokine response to acute exercise in CSCI, given their reduced muscle mass and sympathetic dysfunction (Kouda et al. 2012; Paulson et al. 2013), and-Iin turn, this may contribute to_higher concentrations of pro-inflammatory markers found in CSCI at rest (Davies et al. 2007; Kouda et al. 2012; Segal et al. 1997). Individuals with CSCI are therefore more likely to be in a state of chronic low grade inflammation and at a higher risk for the associated chronic diseases.

Even though increases in immune markers in the CSCI population have been observed in rehabilitation (Kliesch et al. 1996) and exercise studies (Banno et al. 2012), the potential acute immune stimulating effects of hot water immersion have yet to be investigated. Given that $P$ Passive increases in temperature can induce a cytokine response independently of sympathetic activation as shown in myotube experiments where muscle metabolism can be studied without the influence of neural activity (Welc et al. 2012). Therefore, thistemperature elevations may be a promising wayhelp to induce a cytokine response in CSCI with sympathetic dysfunction. As this population has restricted ability to perform and limited access to exercise, any intervention 
that may support or improve immune function and the resting cytokine profile would be of great practical relevance. Therefore, the aim of this study was to measure the effects of 60-min hot water immersion on the acute cytokine and leukocyte response in CSCI. We hypothesise that a temperature-related cytokine response and concomitant increase in leukocyte numbers will be observed in CSCI despite sympathetic dysfunction.

\section{Materials and methods}

\section{Ethical approval}

This study was approved by the local Ethics committee (The Human Investigation Committee, Wakayama Medical University, Japan). Informed consent was obtained in writing from all individual participants included in the study.

\section{Participants}

Eight complete data sets of male participants with a motor complete CSCI and 10 complete data sets of able-bodied (AB) male control participants were collected in this study. One CSCI (indication of autonomic dysreflexia) and $2 \mathrm{AB}$ participants (elevated resting adrenaline levels of over $100 \mathrm{pg} / \mathrm{mL}$ ) were excluded from further analysis, leaving a total number of 7 CSCI and 8 AB participants. A summary of their characteristics is presented in Table 1.

\section{\{insert Table 1 around here\}}

\section{Experimental design}

Data were collected at two different laboratories with $3 \mathrm{CSCI}$ and $3 \mathrm{AB}$ participants tested at one location, the remaining participants at the other location; if equipment differed at the locations the details of both equipment types are hence given. Upon arrival, participants were given a standardised meal consisting of white bread and water ad libitum; they were not allowed any 


\section{Data collection}

Following a $30 \mathrm{~min}$ rest, oesophageal temperature was noted and participants were lifted into the water and immersed to the neck (sternoclavicular notch) for $60 \mathrm{~min}$. The time of day at immersion was 11:45 - 15:45 for all participants. Water temperature was set at a level $2.0^{\circ} \mathrm{C}$ above the individuals' resting oesophageal temperature and measured continuously at the top and bottom of the tank, using the same thermometer as for oesophageal temperature measurements. In the post-immersion period, participants sat at room temperature $\left(26.6 \pm 0.6{ }^{\circ} \mathrm{C}\right)$ and were allowed to do non-strenuous tasks such as reading or watching television. Drinking water preheated to the temperature of the water in the immersion tank was given ad libitum. Sweat loss between pre and $1 \mathrm{~h}$ post immersion was determined by calculating the difference between body mass gain/loss, water intake and excreted urine volume. 
Blood samples were collected into $\mathrm{K}_{3}$ EDTA containers and serum separator tubes after removing the first fraction at rest, 30min and 60min during immersion, and $1 \mathrm{~h}, 2 \mathrm{~h}, 3 \mathrm{~h}$, and $4 \mathrm{~h}$ post immersion.

\section{Analytical methods}

Plasma concentrations of a range of parameters were determined using enzyme-linked immunosorbent assay (ELISA) kits (IL-6, IL-1ra, IL-8, tumor necrosis factor $\alpha(T N F-\alpha)$, soluble intercellular adhesion molecule 1 (sICAM-1), soluble L-selectin (sL-selectin): R\&D systems) according to the manufacturers' instructions using a microplate reader (SH-9000Lab, Corona Electric Co Ltd., Hitachinaka, Japan). All samples from the same participant were analysed on the same microplate. The coefficient of variation $(\mathrm{CV})$ of duplicate samples analysis was $6.2 \pm$ $5.1 \%$ (IL-6), $4.8 \pm 5.2 \%$ (IL-1ra), $4.3 \pm 3.7 \%$ (IL-8), $8.2 \pm 6.6 \%$ (TNF- $\alpha$ ), $3.0 \pm 2.8 \%$ (sICAM1), and $2.9 \pm 2.4 \%$ (sL-selectin). The following parameters were measured by a specialised company (SRL, Tokyo, Japan), with CVs (given in brackets) computed by analysis of standards: Cortisol $(7.6 \%)$ by electrochemiluminescence; adrenaline $(7.0 \%)$ and noradrenaline $(8.8 \%)$ by high-performance liquid chromatography, and blood osmolality $(0.3 \%)$ by the cryoscopic method. Blood counts were performed with a cell counter (SYSMEX XE-5000 and XT-1800i, Kobe, Japan).

\section{Data processing and statistical analyses}

Concentration of all plasma parameters were corrected for changes in plasma volume from rest, blood cell counts for changes in blood volume from rest, according to the methods by Dill and Costill (1974). The SPSS 21.0 statistical package (SPSS Inc., Chicago IL, USA) was used for all statistical analyses. Normality was checked with the Shapiro Wilk test, homogeneity with Levene's statistic. Means and standard deviations were computed for normally distributed 
variables, medians and quartiles for all other variables. Data violating normality and homogeneity assumptions were converted using logarithmic and inverse transformations. Twoway (group by time) repeated measures analyses of variance (ANOVA) with post-hoc Sidak tests applied or Wilcoxon signed ranks test for data violating normality and/or homogeneity assumptions were performed for data analysis of the immersion trial. Independent samples student's t-tests for parametric data, or Mann-Whitney U tests for non-parametric data were performed for group comparisons of single parameters. Statistical significance was accepted at P $<0.05$.

\section{Results}

Hot water immersion increased-resulted in an IL-6 plasma concentration by-mean increase of $133 \pm 144 \%$ in both groups (effect of time, $\mathrm{P}=0.001)$, $)$. On a group level, IL-6 plasma concentrations werewith a $68 \pm 38 \%$ higher $\mathrm{H}-6$ - concentration-in CSCI (effect of group, $\mathrm{P}=$ 0.06). The mean increase of IL-8 plasma concentrations increased bywas $14 \pm 11 \%$ in both groups (effect of time, $\mathrm{P}=0.02)$, with no difference between groups $(\mathrm{P}=0.23)$. Likewise, the mean increase of IL-1ra plasma concentration increased bywas $18 \pm 17 \%$ in both groups (effect of time, $\mathrm{P}=0.05)$, with no difference between groups $(\mathrm{P}=0.23)$ (Fig. 1$)$. In both groups, the plasma concentration of the adhesion molecule sL-selectin decreased by $4 \%$ (effect of time, $\mathrm{P}=0.03$ ), whereas no change was observed in ICAM-1 (effect of time, $\mathrm{P}=0.46$ ) (Table 2). No group differences and no elevations following immersion were found for TNF- $\alpha$ (Table 2).

Plasma concentrations of both adrenaline and noradrenaline were significantly reduced in CSCI (effect of group, $\mathrm{P}<0.05)$, with no group difference in plasma cortisol concentration $(\mathrm{P}=0.76$, Fig. 2). However, group $\mathrm{x}$ time interactions in both noradrenaline $(\mathrm{P}=0.01)$ and cortisol $(\mathrm{P}=$ 0.006) indicated a different temporal development of these parameters in the groups. The 
intervention further resulted in an increase in numbers of leukocytes, particularly in neutrophils, lymphocytes and monocytes (Fig 3, Table 2).

Heart rate during immersion increased significantly in both groups (effect of time, $\mathrm{P}<0.001$ ), however, a group x time interaction $(\mathrm{P}<0.001)$ indicates $\underline{\mathrm{d}}$ a larger increase for $\mathrm{AB}$ (Table 3$)$. Additionally, group effects for systolic, diastolic and pulse pressures were found during immersion $(\mathrm{P}<0.05)$, a group $\mathrm{x}$ time interaction $(\mathrm{P}<0.001)$ in diastolic blood pressure indicating an increase in CSCI and a decrease in AB during immersion.

During immersion, core temperature increased at the same rate in both groups (Fig. 4). Core temperature at rest (CSCI: $37.7 \pm 0.45^{\circ} \mathrm{C}, \mathrm{AB}: 37.4 \pm 0.27^{\circ} \mathrm{C}$, effect of group, $\left.\mathrm{P}=0.15\right)$ and the maximum core temperature elevation did not differ between groups $\left(\mathrm{CSCI}:+2.19 \pm 0.38{ }^{\circ} \mathrm{C}, \mathrm{AB}\right.$ : $+2.16 \pm 0.32{ }^{\circ} \mathrm{C}, \mathrm{P}=0.66$ ). Core temperature recovered more slowly in CSCI than in $\mathrm{AB}$, with significant elevations until 90 min post immersion (Fig. 4, P < 0.05). Despite differences in sweat loss (CSCI: $0.43 \pm 0.39 \mathrm{~L} ; \mathrm{AB}: 1.03 \pm 0.47 \mathrm{~L}$, effect of group, $\mathrm{P}=0.04)$, blood osmolality and plasma volume showed a similar development over time in both groups (Table 2). The water ingested during immersion (CSCI: $0.31 \pm 0.28 \mathrm{~L} ; \mathrm{AB}: 0.31 \pm 0.15 \mathrm{~L})$ and the whole experiment including recovery $(\mathrm{CSCI}$ : $0.68 \pm 0.43 \mathrm{~L} ; \mathrm{AB}: 0.66 \pm 0.30 \mathrm{~L})$ did not differ between groups $(\mathrm{P}>$ $0.05)$.

\section{Discussion}

\section{Markers of inflammation}

This is the first study to show an acute cytokine response induced by hot water immersion in CSCI. Our findings support the concept that hyperthermia can mount an acute cytokine response 
independently of sympathetic activation, as both noradrenaline and adrenaline remained at resting levels. Further, both the heart rate and pulse pressure were significantly reduced in CSCI, with a blunted increase in heart rate and no reduction in diastolic blood pressure during immersion in CSCI, all indicative of sympathetic dysfunction. Due to the reduced ability to sweat in CSCI (Bhambhani 2002; Gass et al. 2002), core temperature following immersion remained elevated for longer when compared with $\mathrm{AB}$. However, this did not result in a more pronounced cytokine response, implying that reaching a minimum elevation above resting core temperature is more important than the time spent above resting core temperature.

The elevations in circulating cytokines reported here are in line with animal experiments showing that hyperthermia can independently stimulate local production of IL-6, with five-fold increases in soleus muscle IL-6 mRNA in mice (Welc et al. 2012). Heat shock factors contribute to the activation of IL-6 synthesis during hyperthermia: As cell temperature rises, protein denaturation results in an increased concentration of heat shock factors, inducing enhanced transcription of IL-6 protein (Welc and Clanton 2013). Increases in IL-6 mRNA exhibit a doseresponse relationship: temperatures of $40.5^{\circ} \mathrm{C}$ do not increase mouse myotube IL-6 mRNA, whereas temperatures of $41{ }^{\circ} \mathrm{C}$ induce 2.5 fold elevations (Welc et al. 2012). Human experiments also suggest that elevations in leukocyte and leukocyte subset counts are more pronounced in interventions that lead to to higher core temperature elevations (Walsh and Whitham 2006). It therefore seems that the immersion protocol used in the present study elevated core (and muscle) temperature over the critical threshold to mount an adequate response. Future research using interventions at a range of immersion temperatures may elucidate the minimum "critical" temperature elevation needed to induce a cytokine response. 
The increases in IL-6 and IL-1ra in CSCI following hot water immersion differ from earlier exercise interventions, where no acute cytokine elevations in the acute post-exercise phase were found in similar populations (Kouda et al. 2012; Paulson et al. 2013), whereas up to 128 -fold increases in IL-6 following the longest and most strenuous forms of exercise are found in the AB population (Pedersen and Febbraio 2008). As our present results show that elevated core temperature seems to independently induce a cytokine response, it seems possible that the reduced active muscle mass in CSCI does not allow for sufficient core temperature elevations during exercise to mount a cytokine response. It is also possible that the $\mathrm{Ca}^{2+}$ dependent pathways during muscle contraction that induce a cytokine response (Pedersen and Febbraio 2008) are not sufficiently activated in CSCI as a result of the drastically reduced active muscle mass. Additionally, as catecholamines independently induce a cytokine response (Steensberg et al. 2001), the blunted catecholamine response in CSCI following exercise interventions (Banno et al. 2012; Kouda et al. 2012; Paulson et al. 2013) may explain the blunted exercise response on cytokine concentrations. The secretion of anti-inflammatory cytokines following exercise may therefore be reduced in CSCI, blunting the anti-inflammatory effects of exercise as described by Gleeson et al. (2011). This seems especially relevant as above average levels of IL-6 reported here and and in the literature (Davies et al. 2007; Kouda et al. 2012; Segal et al. 1997) or elevations in C-reactive protein (Gibson et al. 2008) support the indication of chronic low grade systemic inflammation in CSCI.

Plasma concentrations of cortisol follow a circadian rhythm in both AB and CSCI, decreasing throughout the day from the time of awakening (Zeitzer et al. 2000). In the present study, this natural decrease was disturbed by the immersion intervention, causing a local peak at $1 \mathrm{~h}$ post immersion in both groups. Given the anti-inflammatory effects of cortisol (Gleeson et al. 2011), it is likely that it contributes to the changes in cytokines, adhesion molecules, and elevations in 
leukocyte numbers. Furthermore, IL-6 infusion has been shown to elevate the anti-inflammatory cytokines IL-1ra, IL-10 and plasma levels of cortisol (Steensberg et al. 2003). Supporting this observation, data of the present study show maximum cortisol elevations at $1 \mathrm{~h}$ post immersion in both groups, which follows the immersion-induced increase in IL-6. However, increases in cortisol concentrations have been observed in the absence of IL-6 elevations in both moderately trained (Kouda et al. 2012) and athletic CSCI (Paulson et al. 2013), stressing the importance of alternative mechanisms. The hypothalamic-pituitary-adrenal axis, which is intact in CSCI, is a likely candidate to govern the increase in cortisol following exercise and hyperthermia interventions (Leicht et al. 2013). However, it also appears that the cortisol response is affected by CSCI, as evidenced by a group x time interaction. The parameters collected in the presented study cannot explain this observation, and more research to elucidate the underlying mechanisms is needed.

In contrast to IL-6, IL-8, IL-1ra and cortisol, the other markers of inflammation measured in this study showed no or only very modest responses to hyperthermia. These findings are consistent with the literature: TNF- $\alpha$ has previously been shown to remain constant following exercise interventions, with only slight increases only following the most strenuous types of exercise, such as marathon running (Pedersen and Febbraio 2008). Similarly, sICAM-1 and sL-selectin serum concentrations tend to be unaffected by exercise of a similar duration as used in the current immersion protocol (Shephard 2003). Even though the reductions in plasma sL-selectin observed in the current study were very modest (4\%), they do suggest a decrease in the shedding of these adhesion molecules from leukocytes, and hence, a higher expression of L-selectin on leukocytes following immersion. This suggests a higher capacity for leukocytes to extravasate to potential sites of inflammation, because L-selectin mediates the first interaction between leukocytes and endothelial cells (Shephard 2003). Indeed, fever-range thermal stress promotes 
lymphocyte trafficking across endothelial venules; interestingly, an IL-6 pathway is involved in

\section{Leukocyte profile}

As repeatedly shown following exercise (Foster et al. 1986; Laing et al. 2008; Rhind et al. 1999) and hyperthermia (Brenner et al. 1999; Kappel et al. 1998; Walsh and Whitham 2006) interventions in $\mathrm{AB}$ populations, we report increased neutrophil, lymphocyte and monocyte numbers following hot water immersion. While increased neutrophil counts have been observed earlier following exercise interventions in CSCI populations, lymphocyte numbers remained unchanged in this population (Kouda et al. 2012; Yamanaka et al. 2010). The results of the current study support this observation: when compared with $A B$, lymphocyte number elevations in CSCI are blunted between rest and the end of the immersion period, as indicated by a significant group $\mathrm{x}$ time interaction. It is possible that the different noradrenaline response between groups during immersion causes this first peak during immersion in lymphocyte numbers in AB. In line with this, blocking $\beta$-adrenergic receptors in $\mathrm{AB}$ (Foster et al. 1986) has been demonstrated to reduce the post-exercise increase in lymphocyte numbers. Similarly, exercise in cold water to keep core temperature constant results in a blunted adrenaline response in $\mathrm{AB}$, causing a reduced increase in lymphocyte numbers following exercise (Rhind et al. 1999). Finally, $\alpha$ - or $\beta$-adrenergic blockade in mice demonstrates the importance of adrenergic mechanisms for T cell migration following exercise (Kruger et al. 2008). These data support the 
concept of required catecholamine action to up-regulate lymphocyte numbers during hyperthermia. Lymphocytes are the leukocyte subset most dominantly influenced by $\beta$ adrenergic receptors (Shephard 2003). Hence, they seem to be a cell type particularly susceptible to adrenal activation, as the neutrophil counts during hyperthermia after infusion of propranolol are unaffected (Kappel et al. 1998), and neutrophil counts in the current study did not differ between groups.

In the post exercise (Laing et al. 2008) or post immersion (current study) period, catecholamines in $\mathrm{AB}$ return to resting levels soon after the intervention. Moreover, the reduced adrenaline levels and the limited adrenaline response in CSCI suggest factors other than catecholamines are responsible for the post-immersion increase in leukocytes. It has been suggested that increases in cardiac output may result in higher immune cell numbers in the circulation by way of shear stress on vessels and adhering cells (McCarthy and Dale 1988). Indeed, the present results show differences in the heart rate and blood pressure responses between the groups, but they can only help explain the initial increase in lymphocytes in $\mathrm{AB}$, as values return to resting (blood pressure) or close to resting levels (heart rate) within one hour post exercise. The increases in leukocytes in the recovery period are likely to be mediated by other factors, such as cortisol (Walsh and Whitham 2006), that remain elevated further into the post-immersion period than adrenergic factors.

\section{Practical applications}

The $\mathrm{AB}$ data of the present study are in line with an earlier report, where increases in IL-6, cortisol, and neutrophils in $\mathrm{AB}$ participants were observed following hot water immersion for 120 min (Laing et al. 2008). Notably, the immersion time used in the present study was half the duration of this earlier study, making it more applicable to be used in rehabilitation settings. A 
multitude of immune-stimulating effects of hyperthermia are known today, including cytokine production, increased expression of Toll-like receptors and the major histocompatibility complex, or enhanced migration capability of immune cells (Zhang et al. 2008). Moreover, water immersion has been applied in spinal cord injury rehabilitation settings previously, reducing spasticity and improving functional independence measures (Kesiktas et al. 2004).

As the treatment for CSCI improves, the age and the comorbidities associated with an ageing population increase, which include illnesses related to chronic low grade inflammation. Chronic low grade inflammation has been suggested to be reduced by repeated acute increases in antiinflammatory cytokines (Gleeson et al. 2011). Therefore, by inducing an acute cytokine response through hot water immersion, our findings add another dimension to the benefits of water therapy known today. Future longitudinal randomised controlled trials should investigate the long-term effects of repeated immersion interventions on the resting cytokine profile and/or infection susceptibility in CSCI.

\section{Limitations}

In order to make more evidence-based conclusions regarding the impact of temperature on the cytokine response following exercise and passive water immersion, future studies should measure both muscle and core temperature elevations for either modality and relate it to the cytokine response. By incorporating direct measures of leukocyte activation (for example, cell surface receptor determination or direct cell trafficking analysis) findings derived from soluble plasma parameters investigated in the current study could further be strengthened. If feasible, a resting control condition should be included in future investigations. 


\section{Conclusions}

The passive elevation of core temperature mounts an acute cytokine response and elevates leukocyte subsets in CSCI. The present study lays the foundation to explore water immersion based procedures as an alternative to exercise to induce an acute cytokine response in CSCI.

\section{Acknowledgements}

We thank all participants for their willingness to take part in this study. Appreciation is extended to the physiotherapy and medical teams in Nachi-Katsuura and Wakayama for their contribution during laboratory testing.

This study was supported by grants from the Joint Usage/Research Center of Sports for Persons with Impairments (Tokyo, Japan), and the Research Center of Sports Medicine and Balneology (Natchi-Katsuura, Japan).

\section{Conflict of interests}

There is no conflict of interest

All procedures performed in studies involving human participants were in accordance with the ethical standards of the institutional and national research committee and with the 1964 Helsinki declaration and its later amendments.

\section{References}

Banno M, Nakamura T, Furusawa K et al (2012) Wheelchair half-marathon race increases natural killer cell activity in persons with cervical spinal cord injury. Spinal Cord 50:533-537

Bhambhani Y (2002) Physiology of wheelchair racing in athletes with spinal cord injury. Sports Med 32:23-51 
Brenner IK, Castellani JW, Gabaree C et al (1999) Immune changes in humans during cold exposure: effects of prior heating and exercise. J Appl Physiol 87:699-710

Cardenas DD, Hoffman JM, Kirshblum S, McKinley W (2004) Etiology and incidence of rehospitalization after traumatic spinal cord injury: a multicenter analysis. Arch Phys Med Rehabil 85:1757-1763

Chen Q, Fisher DT, Clancy KA et al (2006) Fever-range thermal stress promotes lymphocyte trafficking across high endothelial venules via an interleukin 6 trans-signaling mechanism. Nat Immunol 7:1299-1308

Davies AL, Hayes KC, Dekaban GA (2007) Clinical correlates of elevated serum concentrations of cytokines and autoantibodies in patients with spinal cord injury. Arch Phys Med Rehabil 88:1384-1393

DeVivo MJ, Krause JS, Lammertse DP (1999) Recent trends in mortality and causes of death among persons with spinal cord injury. Arch Phys Med Rehabil 80:1411-1419

Dill DB, Costill DL (1974) Calculation of percentage changes in volumes of blood, plasma, and red cells in dehydration. J Appl Physiol 37:247-248

Foster NK, Martyn JB, Rangno RE, Hogg JC, Pardy RL (1986) Leukocytosis of exercise: role of cardiac output and catecholamines. J Appl Physiol 61:2218-2223

Gass EM, Gass GC, Pitetti K (2002) Thermoregulatory responses to exercise and warm water immersion in physically trained men with tetraplegia. Spinal Cord 40:474-480

Gibson AE, Buchholz AC, Martin Ginis KA, SHAPE-SCI Research Group (2008) C-Reactive protein in adults with chronic spinal cord injury: increased chronic inflammation in tetraplegia vs paraplegia. Spinal Cord 46:616-621

Gleeson M, Bishop NC, Stensel DJ, Lindley MR, Mastana SS, Nimmo MA (2011) The antiinflammatory effects of exercise: mechanisms and implications for the prevention and treatment of disease. Nat Rev Immunol 11:607-615

Kappel M, Poulsen TD, Hansen MB, Galbo H, Pedersen BK (1998) Somatostatin attenuates the hyperthermia induced increase in neutrophil concentration. Eur J Appl Physiol Occup Physiol $77: 149-156$

Kappel M, Stadeager C, Tvede N, Galbo H, Pedersen BK (1991) Effects of in vivo hyperthermia on natural killer cell activity, in vitro proliferative responses and blood mononuclear cell subpopulations. Clin Exp Immunol 84:175-180

Kesiktas N, Paker N, Erdogan N, Gulsen G, Bicki D, Yilmaz H (2004) The use of hydrotherapy for the management of spasticity. Neurorehabil Neural Repair 18:268-273

Kliesch WF, Cruse JM, Lewis RE, Bishop GR, Brackin B, Lampton JA (1996) Restoration of depressed immune function in spinal cord injury patients receiving rehabilitation therapy. Paraplegia 34:82-90 
Kouda K, Furusawa K, Sugiyama H et al (2012) Does 20-min arm crank ergometer exercise increase plasma interleukin-6 in individuals with cervical spinal cord injury? Eur J Appl Physiol 112:597-604

Kruger K, Lechtermann A, Fobker M, Volker K, Mooren FC (2008) Exercise-induced redistribution of $\mathrm{T}$ lymphocytes is regulated by adrenergic mechanisms. Brain Behav Immun $22: 324-338$

Laing SJ, Jackson AR, Walters R et al (2008) Human blood neutrophil responses to prolonged exercise with and without a thermal clamp. J Appl Physiol 104:20-26

Leicht CA, Goosey-Tolfrey VL, Bishop NC (2013) Spinal cord injury: Known and possible influences on the immune response to exercise. Exerc Immunol Rev 19:146-165

McCarthy DA, Dale MM (1988) The leucocytosis of exercise. A review and model. Sports Med 6:333-363

Nagao F, Suzui M, Takeda K, Yagita H, Okumura K (2000) Mobilization of NK cells by exercise: downmodulation of adhesion molecules on NK cells by catecholamines. Am J Physiol Regul Integr Comp Physiol 279:R1251-6

Paulson TAW, Goosey-Tolfrey VL, Lenton JP, Leicht CA, Bishop NC (2013) Spinal cord injury level and the circulating cytokine response to strenuous exercise. Med Sci Sports Exerc 45:16491655

Pedersen BK, Febbraio MA (2008) Muscle as an endocrine organ: focus on muscle-derived interleukin-6. Physiol Rev 88:1379-1406

Rhind SG, Gannon GA, Shek PN et al (1999) Contribution of exertional hyperthermia to sympathoadrenal-mediated lymphocyte subset redistribution. J Appl Physiol 87:1178-1185

Segal JL, Gonzales E, Yousefi S, Jamshidipour L, Brunnemann SR (1997) Circulating levels of IL-2R, ICAM-1, and IL-6 in spinal cord injuries. Arch Phys Med Rehabil 78:44-47

Shephard RJ (2003) Adhesion molecules, catecholamines and leucocyte redistribution during and following exercise. Sports Med 33:261-284

Starkie RL, Rolland J, Febbraio MA (2001) Effect of adrenergic blockade on lymphocyte cytokine production at rest and during exercise. Am J Physiol Cell Physiol 281:C1233-40

Steensberg A, Fischer CP, Keller C, Moller K, Pedersen BK (2003) IL-6 enhances plasma IL1ra, IL-10, and cortisol in humans. Am J Physiol Endocrinol Metab 285:E433-7

Steensberg A, Toft AD, Schjerling P, Halkjaer-Kristensen J, Pedersen BK (2001) Plasma interleukin-6 during strenuous exercise: role of epinephrine. Am J Physiol Cell Physiol 281:C1001-4

Walsh NP, Whitham M (2006) Exercising in environmental extremes: a greater threat to immune function? Sports Med 36:941-976 
Welc SS, Clanton TL (2013) The regulation of interleukin-6 implicates skeletal muscle as an integrative stress sensor and endocrine organ. Exp Physiol 98:359-371

Welc SS, Phillips NA, Oca-Cossio J, Wallet SM, Chen DL, Clanton TL (2012) Hyperthermia increases interleukin-6 in mouse skeletal muscle. Am J Physiol Cell Physiol 303:C455-66

Yamanaka M, Furusawa K, Sugiyama $\mathrm{H}$ et al (2010) Impaired immune response to voluntary arm-crank ergometer exercise in patients with cervical spinal cord injury. Spinal Cord 48:734739

Zeitzer JM, Ayas NT, Shea SA, Brown R, Czeisler CA (2000) Absence of detectable melatonin and preservation of cortisol and thyrotropin rhythms in tetraplegia. J Clin Endocrinol Metab $85: 2189-2196$

Zhang HG, Mehta K, Cohen P, Guha C (2008) Hyperthermia on immune regulation: a temperature's story. Cancer Lett 271:191-204 


\section{Figure legends}

Fig. 1 Interleukin-6 (IL-6), IL-8 and IL-1ra response to 60 min of hot water immersion (imm). IL-6 - Significant effect of time $(\mathrm{P}=0.001): \mathrm{a}<\mathrm{b}<\mathrm{c} ;$ IL-8 - significant effect of time $(\mathrm{P}=0.02)$ : $\mathrm{a}<\mathrm{b}$; IL-1ra - significant effect of time $(\mathrm{P}=0.05): \mathrm{a}<\mathrm{b}$

Fig. 2 Adrenaline, noradrenaline and cortisol response to $60 \mathrm{~min}$ of hot water immersion (imm). Significant differences $(\mathrm{P}<0.05)$ : Adrenaline, noradrenaline: main effect of group, Noradrenaline, cortisol: group x time interaction, $\underline{\text { a }}$ different from rest

Fig. 3 Blood cell count response to $60 \mathrm{~min}$ of hot water immersion (imm). Significant differences $(\mathrm{P}<0.05)$ : Lymphocytes: main effect of group and group $\mathrm{x}$ time interaction, ${ }^{\text {adifferent }}$ from rest, ${ }^{\mathrm{b}}$ different from $1 \mathrm{~h}$ post, ${ }^{\mathrm{c}}$ different from $30 \mathrm{~min},{ }^{\mathrm{d}}$ difference between $2 \mathrm{~h}, 3 \mathrm{~h}$ and $4 \mathrm{~h}$ post

Fig. 4 Core temperature elevations from rest during and following hot water immersion (imm). $\underline{a} *$ Significant difference between groups $(\mathrm{P}<0.05)$ 

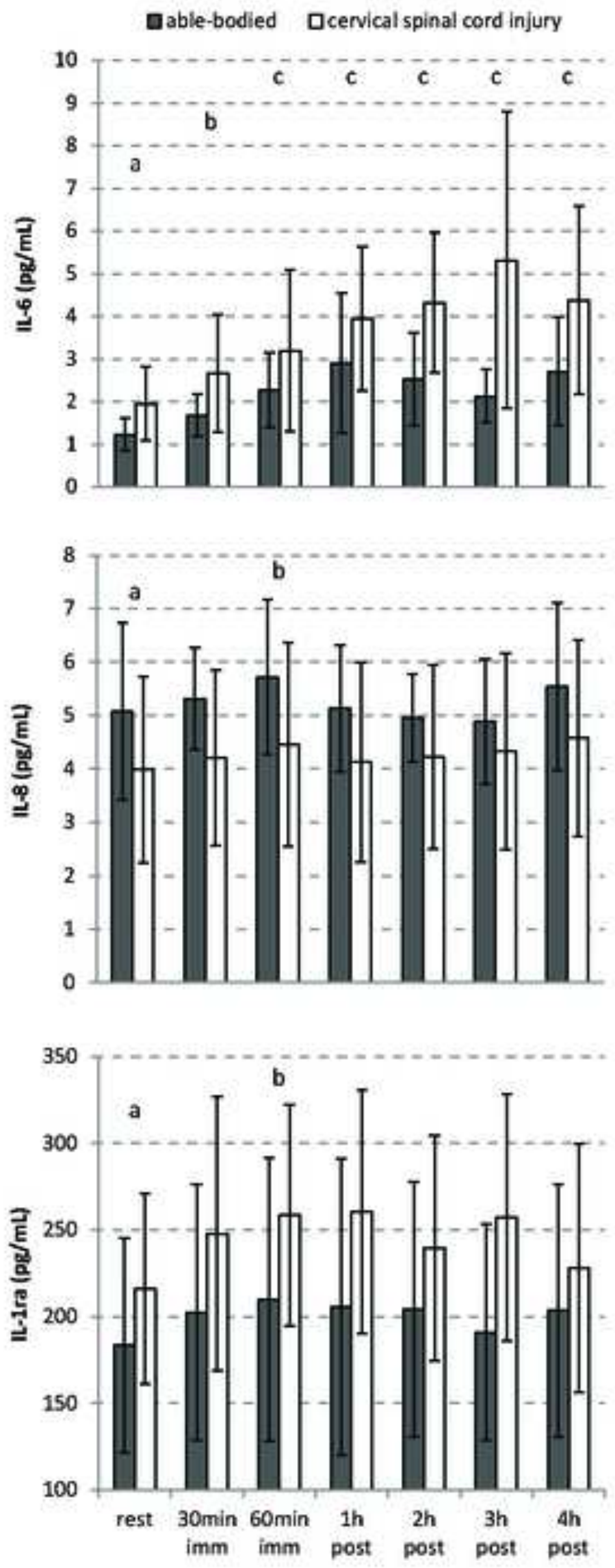
Click here to download Figure: figure 2 29.04.15.tiff
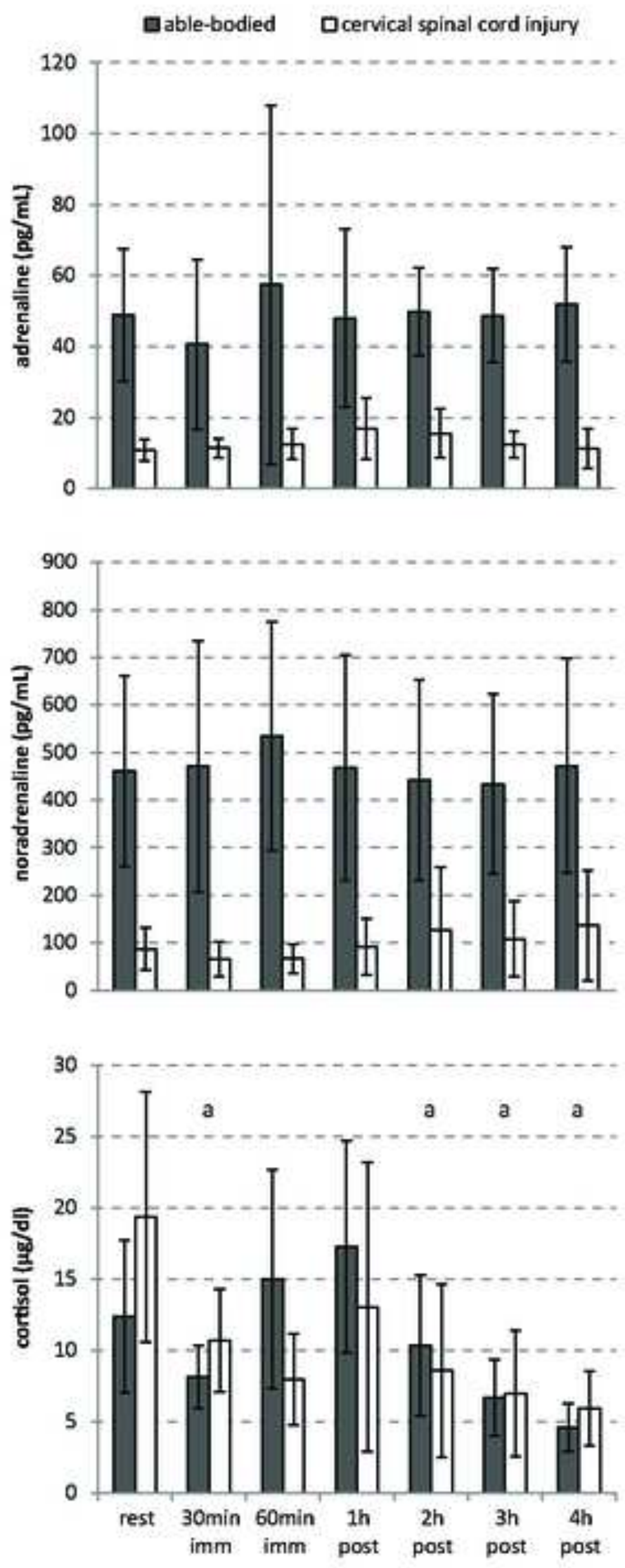

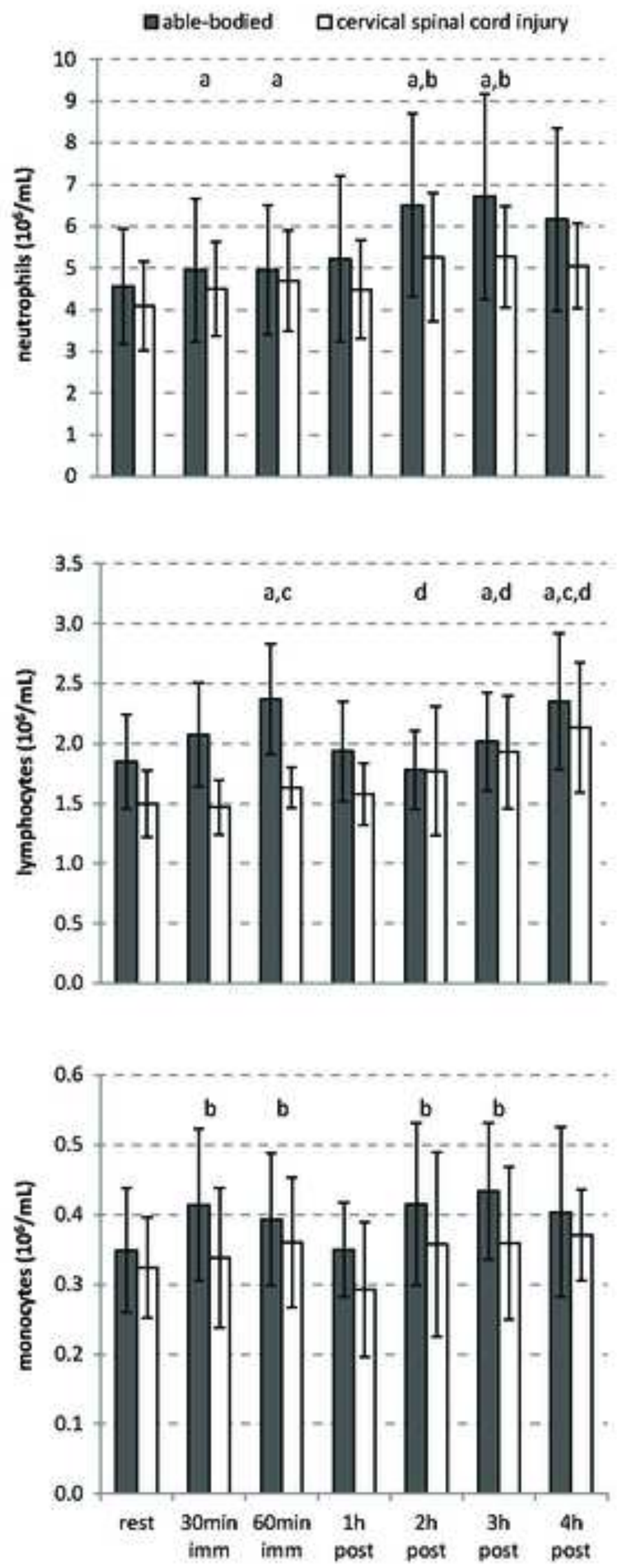
$\square$ able-bodied $\square$ cervical spinal cord injury

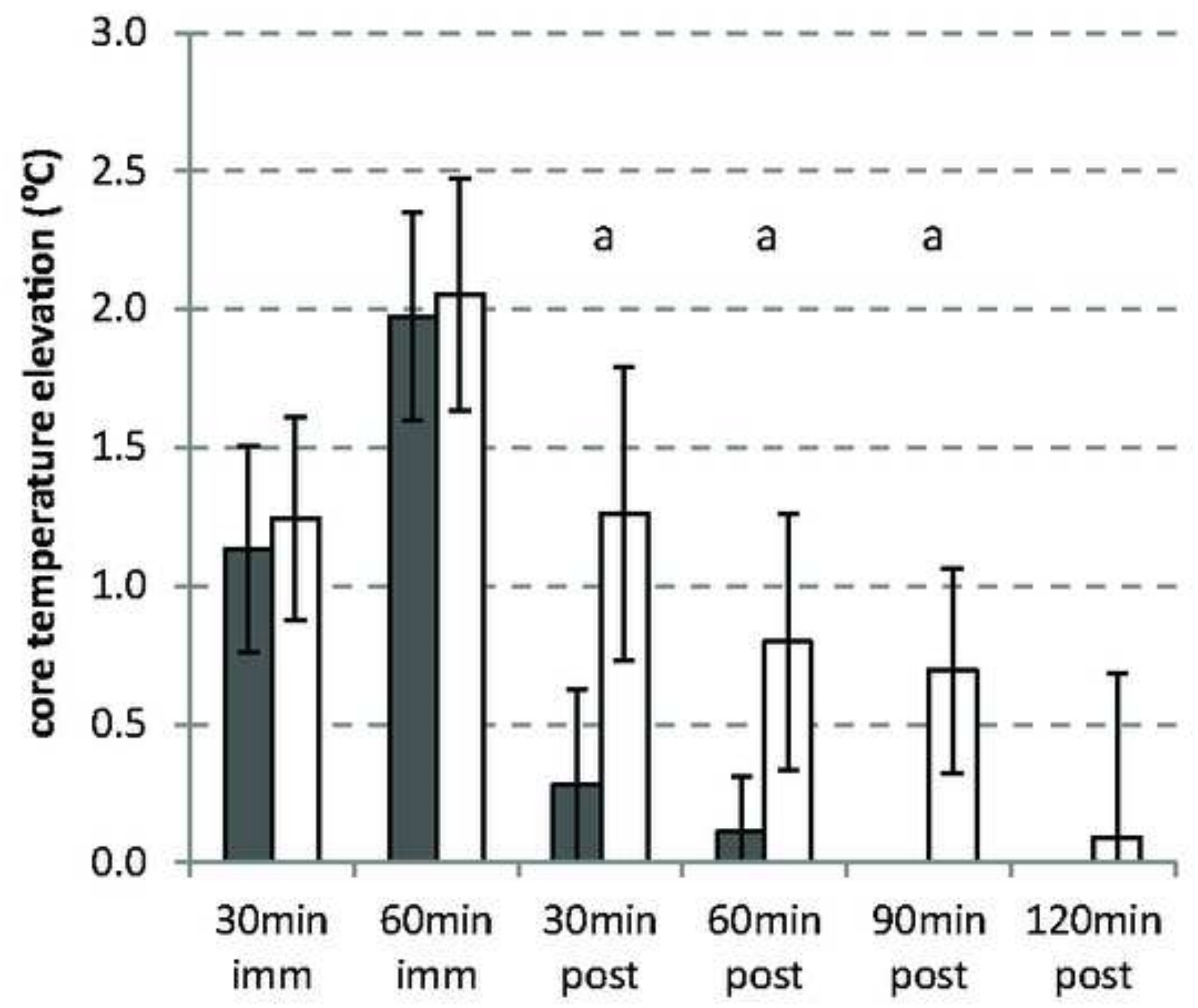


Table 1 Participants' characteristics

\begin{tabular}{lcc}
\hline & $\begin{array}{c}\text { Cervical spinal cord injury } \\
(\mathbf{N}=7)\end{array}$ & $\begin{array}{c}\text { Able-bodied } \\
(\mathbf{N}=8)\end{array}$ \\
\hline Age [years] & $39 \pm 12$ & $41 \pm 8$ \\
Body mass [kg] & $54 \pm 9^{*}$ & $71 \pm 8$ \\
Height [cm] & $168 \pm 9$ & $171 \pm 6$ \\
Sporting activity & $0.4 \pm 1.1$ & $0.5 \pm 0.9$ \\
[h/week] & C5-C8: ASIA A (N=6) and & \\
Spinal cord & B (N=1) & \\
injury details & $9 \pm 7$ & not applicable \\
Time since & & \\
injury [years] & & \\
\hline
\end{tabular}

ASIA, American spinal injury association impairment scale; C, cervical. Data are means \pm SD. *Significant difference between groups $(\mathrm{P}<0.05)$. 
Table 2 Inflammation markers, leukocyte counts and hydration markers in response to 60 min of hot water immersion

\begin{tabular}{|c|c|c|c|c|c|c|c|c|c|}
\hline Parameter & Group & Rest & $\begin{array}{l}30 \text { min } \\
\text { immersion }\end{array}$ & $\begin{array}{l}60 \text { min } \\
\text { immersion }\end{array}$ & 1h post & $2 \mathrm{~h}$ post & 3h post & 4h post & $\begin{array}{l}\text { Significant P- } \\
\text { values (time } \\
\text { effects) }\end{array}$ \\
\hline TNF- $\alpha$ & CSCI & $1.34 \pm 0.26$ & $1.31 \pm 0.26$ & $1.22 \pm 0.30$ & $1.22 \pm 0.33$ & $1.16 \pm 0.37$ & $1.19 \pm 0.31$ & $1.22 \pm 0.23$ & \\
\hline$[p g / m L]$ & $\mathrm{AB}$ & $1.08 \pm 0.21$ & $1.15 \pm 0.24$ & $1.14 \pm 0.22$ & $1.08 \pm 0.24$ & $1.11 \pm 0.11$ & $1.17 \pm 0.16$ & $1.11 \pm 0.21$ & \\
\hline sL-selectin & CSCI & $0.98 \pm 0.18$ & $1.00 \pm 0.21$ & $0.99 \pm 0.18$ & $0.95 \pm 0.19$ & $0.97 \pm 0.19$ & $0.95 \pm 0.20$ & $0.97 \pm 0.21$ & $0.03: 1 \mathrm{~h}<$ rest \\
\hline$[\mu \mathrm{g} / \mathrm{mL}]$ & $\mathrm{AB}$ & $1.10 \pm 0.25$ & $1.12 \pm 0.23$ & $1.10 \pm 0.24$ & $1.05 \pm 0.20$ & $1.06 \pm 0.20$ & $1.08 \pm 0.20$ & $1.08 \pm 0.21$ & \\
\hline sICAM-1 & CSCI & $190 \pm 42$ & $191 \pm 42$ & $192 \pm 41$ & $184 \pm 47$ & $193 \pm 46$ & $194 \pm 48$ & $194 \pm 49$ & \\
\hline$[\mathrm{ng} / \mathrm{mL}]$ & $\mathrm{AB}$ & $181 \pm 68$ & $187 \pm 74$ & $179 \pm 70$ & $181 \pm 71$ & $182 \pm 75$ & $191 \pm 84$ & $165 \pm 65$ & \\
\hline Leukocytes & CSCI & $6.11 \pm 1.03$ & $6.53 \pm 1.28$ & $6.89 \pm 1.27$ & $6.55 \pm 1.25$ & $7.59 \pm 1.95$ & $7.42 \pm 1.38$ & $7.75 \pm 1.14$ & $<0.001:$ \\
\hline$[\times 106 / \mathrm{mL}]$ & $\mathrm{AB}$ & $6.92 \pm 1.53$ & $7.65 \pm 1.93$ & $7.92 \pm 1.72$ & $7.69 \pm 1.98$ & $8.91 \pm 2.18$ & $9.35 \pm 2.51$ & $9.10 \pm 2.33$ & $\begin{array}{l}\text { rest }<30 \mathrm{~min}-4 \mathrm{~h} \text {; } \\
1 \mathrm{~h}<2 \mathrm{~h}-4 \mathrm{~h}\end{array}$ \\
\hline Osmolality & CSCI* & $283 \pm 4$ & $283 \pm 4$ & $281 \pm 4$ & $279 \pm 6$ & $278 \pm 6$ & $278 \pm 6$ & $279 \pm 6$ & $<0.05: 2 \mathrm{~h}, 3 \mathrm{~h}, 4 \mathrm{~h}<\mathrm{rest}$ \\
\hline$\left[\mathrm{mOsm} / \mathrm{kgH}_{2} \mathrm{O}\right]$ & $\mathrm{AB}$ & $288 \pm 2$ & $290 \pm 3$ & $290 \pm 3$ & $287 \pm 4$ & $287 \pm 3$ & $286 \pm 3$ & $286 \pm 3$ & \\
\hline Plasma volume & $\mathrm{CSCI}^{*}$ & $59.9 \pm 3.7$ & $63.8 \pm 3.7$ & $63.9 \pm 4.5$ & $61.3 \pm 5.3$ & $61.4 \pm 5.8$ & $61.8 \pm 5.8$ & $61.0 \pm 5.9$ & 0.003: rest<30min; \\
\hline$[\%]$ & $\mathrm{AB}$ & $55.7 \pm 1.5$ & $58.4 \pm 2.5$ & $56.6 \pm 2.3$ & $54.8 \pm 2.9$ & $54.7 \pm 2.9$ & $54.6 \pm 2.1$ & $54.5 \pm 2.2$ & $1 \mathrm{~h}, 2 \mathrm{~h}, 3 \mathrm{~h}<30 \mathrm{~min}$ \\
\hline
\end{tabular}

TNF, tumor necrosis factor; ICAM, intercellular adhesion molecule; CSCI, cervical spinal cord injury; AB, able-bodied.

Data are means $\pm \mathrm{SD}$. *Main effect of group $(\mathrm{P}<0.05)$. 
Table 3 Heart rate and pulse pressure response to 60 min of hot water immersion

\begin{tabular}{|c|c|c|c|c|c|c|c|c|}
\hline Parameter & Group & Rest & $\begin{array}{l}15 \text { min } \\
\text { immersion }\end{array}$ & $\begin{array}{l}30 \text { min } \\
\text { immersion }\end{array}$ & $\begin{array}{l}45 \text { min } \\
\text { immersion }\end{array}$ & $\begin{array}{l}60 \text { min } \\
\text { immersion }\end{array}$ & $\begin{array}{l}\text { 1h } \\
\text { post }\end{array}$ & $\begin{array}{l}\text { Significant P-values (time and } \\
\text { interaction effects) }\end{array}$ \\
\hline $\begin{array}{l}\text { Heart rate } \\
{[\mathrm{b} / \mathrm{min}]}\end{array}$ & $\begin{array}{l}\text { CSCI* } \\
\mathrm{AB}\end{array}$ & $\begin{array}{l}76 \pm 13 \\
75 \pm 10\end{array}$ & $\begin{array}{l}77 \pm 12 \\
90 \pm 9\end{array}$ & $\begin{array}{l}82 \pm 13 \\
104 \pm 12\end{array}$ & $\begin{array}{l}84 \pm 12 \\
110 \pm 14\end{array}$ & $\begin{array}{l}85 \pm 14 \\
114 \pm 12\end{array}$ & $\begin{array}{l}84 \pm 16 \\
85 \pm 13\end{array}$ & $\begin{array}{l}<0.001 \text { (time): } \\
\text { rest, } 15 \min <30 \mathrm{~min}<45 \mathrm{~min}, 60 \mathrm{~min} \text {; } \\
\text { rest }<1 \mathrm{~h} \text { post } \\
<0.001 \text { (group } \mathrm{x} \text { time) }\end{array}$ \\
\hline $\begin{array}{l}\text { Pulse pressure } \\
\text { [mmHg] }\end{array}$ & $\begin{array}{l}\mathrm{CSCI}^{*} \\
\mathrm{AB}\end{array}$ & $\begin{array}{l}34 \pm 12 \\
40 \pm 12\end{array}$ & $\begin{array}{l}37 \pm 11 \\
42 \pm 6\end{array}$ & $\begin{array}{l}36 \pm 13 \\
51 \pm 7\end{array}$ & $\begin{array}{l}36 \pm 14 \\
53 \pm 7\end{array}$ & $\begin{array}{l}37 \pm 9 \\
52 \pm 6\end{array}$ & $\begin{array}{l}31 \pm 7 \\
38 \pm 10\end{array}$ & 0.002 (time) \\
\hline $\begin{array}{l}\text { Systolic blood } \\
\text { pressure } \\
{[\mathrm{mmHg}]}\end{array}$ & $\frac{\mathrm{CSCI}^{*}}{\underline{\mathrm{AB}}}$ & $\frac{89 \pm 24}{\underline{121 \pm 22}}$ & $\frac{108 \pm 17}{\underline{118 \pm 8}}$ & $\frac{100 \pm 18}{\underline{119 \pm 9}}$ & $\frac{102 \pm 22}{\underline{120 \pm 6}}$ & $\frac{104 \pm 16}{\underline{120 \pm 6}}$ & $\begin{array}{l}\frac{86 \pm 12}{115 \pm 18} \\
\underline{15}\end{array}$ & $\underline{0.03 \text { (time) }}$ \\
\hline $\begin{array}{l}\text { Diastolic blood } \\
\text { pressure } \\
\text { [mmHg] }\end{array}$ & $\frac{\mathrm{CSCI}^{*}}{\underline{\mathrm{AB}}}$ & $\underline{55 \pm 15}$ & $\underline{\frac{70 \pm 8}{76 \pm 11}}$ & $\underline{\underline{64 \pm 9}}$ & $\frac{66 \pm 10}{\underline{67 \pm 7}}$ & $\frac{\underline{66 \pm 8}}{\underline{67 \pm 8}}$ & $\frac{54 \pm 12}{78 \pm 10}$ & $\leq 0.001$ (group x time) \\
\hline
\end{tabular}

CSCI, cervical spinal cord injury; AB, able-bodied.

Data are means $\pm \mathrm{SD}$. *Main effect of group $(\mathrm{P}<0.05)$. 